\title{
Morphological variations of mangosteen fruits from Luzon and Mindanao Islands, the Philippines
}

\author{
J. BERAME ${ }^{1,4, \boldsymbol{\varphi}}$, N. LAWSIN ${ }^{2,4}$, F. MIGUEL ${ }^{3,4}$, J. CHAVEZ ${ }^{4}$ \\ ${ }^{1}$ Department of Education Biology, Caraga State University. Ampayon 8600, Butuan City, Philippines. Tel.: +63-133-8341-2786, \\ vemail: janveel@yahoo.com \\ ${ }^{2}$ Department ofEducation, Navotas Polytechnic College. Bangus St., Corner, Apahap, Navotas City 1409, Philippines \\ ${ }^{3}$ Ramon Magsaysay High School. España, Manila, Philippines \\ ${ }^{4}$ Department of Biology, De La Salle University. 2401 Taft Avenue, 1004 Manila, Philippines
}

Manuscript received: 11 March 2020. Revision accepted: 16 June 2020.

\begin{abstract}
Berame J, Lawsin N, Miguel F, Chavez J. 2020. Morphological variations of mangosteen fruits from Luzon and Mindanao Islands, the Philippines. Biodiversitas 21: 3094-3100. Luzon and Mindanao islands in the Philippines are the important mangosteen producing provinces whose growing areas are scattered on these two islands. With this, mangosteen variability was detected based on field fruit collections in summer of 2019. The morphological variations of mangosteen fruits were observed and collected in Quezon Province in Luzon and Davao-Zamboanga Provinces in Mindanao based on the total number of 175 mangosteen trees. The main objectives of the research were to find out the morphological variations of mangosteen fruits and using Tomato Analyzer 4.0 to determine the morphological characters that can be used to differentiate mangosteen accessions in the Philippines. The variables include fruit shape index (external and internal), curve fruit shape index, asymmetry, internal eccentricity and weight of the ripe fruits. The results show that fruit characters like ellipsoidal, circular, rectangular, lobe shape, size, pericarp area, and pericarp thickness. are highly resemblance particularly in its fruit shape characters, and even sharing a similar taste of ripe fruits. Data revealed that Garcinia mangostana shared a similar character with Garcinia malaccensis even though they are from different geographical areas. Based on the morphological variations and characters, the two varieties of mangosteen fruits in the Philippines, G. mangostana and G. malaccensis, are so closely related that they could be combined together as one species as identified in the morphological analysis of this study.
\end{abstract}

Keywords: Mangosteen, morphology, tomato analyzer 4.0, variation

\section{INTRODUCTION}

Mangostana species are about hundreds of species in the family Guttiferae (Clusiaceae) across West Africa including tropical countries in Asia like the Philippines (Cruz 2011). The African mangosteens or Imbe (Garcinia livingstonei T. Anderson) are slightly larger than lemon drop type, deep-purple, round, and shape fruits capped with light green calyx at the stem end. In the Philippines, this fruit grows both on lowland and highland with diverse environmental conditions like soil, climate, or weather. It is derived from forests or backyards without any intensive maintenance effort (Da-Amas 2014). Some authors reported that the morphological differences of mangosteen in Jolo, Sulu in Mindanao was larger and had a thicker rind than in Luzon, Singapore, and Saigon (Burkill 2015; Wester 2011)

Many of the mangostana species basically bear sweet, dark purple fruit that is most treasured product of the Guttiferae family because of its health benefits (Altendorf 2018). As the "queen of tropical fruits" in the country (Aizat et al. 2019) where its species has probably been cultivated for around thousand years already (Nazre et al. 2018) and Garcinia mangostana L. and Garcinia malaccensis T. Anderson trees are strictly tropical with a narrow range of adaptability and its traditional vegetative propagation methods have proven difficult with the majority of mangostana usually propagated from seed (Hapsari et al. 2018).

Meanwhile, mangostana grows very slowly and the same as its fruiting season. This long juvenile phase and irregular bearings of the trees are major concerns of many growers and essential areas to be addressed for crop improvement (Ovalle-Magallanes et al. 2017) because its tropical fruits have received huge attention in the medical field in the Philippines and abroad. In order to develop strategies for mangostana fruit, improvement and preserving unique Garcinia germplasm is necessary to have an understanding of the genetic diversity within $G$. mangostana and among Garcinia species (Qinet al. 2017).

Henceforth, mangosteens in the Philippines catch the attention of this study. Its fruits diversity was prevalent from its geographical locations in Luzon and Mindanao islands in the Philippines. Like for example, its fruit shapes differ from each other (Sobir and Poerwanto 2016) from Quezon Province in Luzon and Davao-Zamboanga Provinces in Mindanao Island. Their shape-size diversity differs from each other. With this, the researchers have the interest to analyze its diversity and relationship through fruit morphometric in the light of this study as stipulated the distinct quantitative inquiry in a biological fruit shapeformed (Ounlert et al. 2017). The morphometric investigation of this study uses the cross-section of sliced ripe mangosteen both G. mangostana and G. malaccensis, 
distance in the landmarks of the fruit samples as the main source of fruit morphological data analyze in the Tomato Analyzer 4.0. Selections and preparations and image collection of mangosteen fruits were also considered. The researchers believed that this technique has more advantageous to investigate the phenotypic variation for mangostana studies in fruit shape classifications (Henderson 2014; Klingenberg and Monteiro 2013; Lihovaet al. 2014), as well as fruit evolutionary analyses in the field of systematics (Borba et al. 2017; Langlade et al. 2015). Besides, there are many analyses have also been applied in plant genetic studies (Langlade et al. 2005; Perez-Perez et al. 2012) in a wide-ranging and non-repetitive technique (Dryden et al. 2014) that involves neither preceding knowledge nor predetermined concepts of the fruit shape features that the researchers wanted to measure.

As mentioned, indirect modifications in any fruit shapes may not be apprehended by exact descriptors; as an alternative. These indirect modifications would be apprehended by fruit morphometric analyses by using the latest technique. Hence, the researcher predetermined techniques for this mangostana fruit shape and size analysis that includes the morphometrics and its features analysis that could possibly have different and complementary analysis. The fruit shape morphometric analysis is unbiased and high-throughput analysis. On the other hand, the mangostana phenotypic features (Mansyah et al. 2013; Fauza et al. 2015) of this study is resulting from morphometric analysis whether nonfigurative features would capture fruit shape variations from the measurements quantities of its angles in degrees and shape/size indices as fractions that best describe specific features of fruit shape variations (Sando 2011; Sobir et al. 2016).

This paper has compiled results of research on morphological variations and characteristics in mangosteen fruits. Investigation was conducted by using one hundred out of 175 samples in order to get better understanding of morphological variations. The objectives of this paper are to provide information about mangosteen variability and using Tomato Analyzer 4.0 to determine the morphological characters that can be used to differentiate mangosteen accessions in the Philippines.

\section{MATERIALS AND METHODS}

This research was conducted in Science and Technology Research Center (STRC) of De La Salle University, Taft Avenue, Manila, Philippines. It involved several steps like fruit collection, preparation of fruit samples, image acquisition, analysis of parameters using Tomato Analyzer 4.0, and analysis of data.

\section{Fruit collection}

Sample of mangosteen fruits was collected from Quezon Province in Luzon and Davao-Zamboanga Provinces in Mindanao. A total of 175 fruits samples were collected and 100 were utilized in the study with 50 fruit samples of $G$. mangostana from Davao-Zamboanga Provinces and 50 fruit samples of $G$. malaccensis in
Quezon Province. The selection was done by physical examination and fruit level of ripening. The fruit samples with external deformities and over riped were removed in the shape-size morphometrics analyzes. Over ripening in fleshy fruit causes shape deformation when cutting the fruit were discarded (Sandra 2011; Whidhiasih et al. 2012).

\section{Preparation of fruit samples}

In the morphometric preparation, the mangosteen fruits were cleaned mechanically from dust and resin using a dry clean cloth. Pedicles or the remnants of the stalk were removed using a sharp cutter to maintain the evenness of the outer lining of the fruit which might affect the measurement. The diameter of each fruit was determined using Mitutoyo Digimatic caliper to determine the average fruit circumference. Digital analytical balance was used to measure the weight of each sample fruit to obtain the average weight of the fruit.

Fruits were cut in longitudinal manner passing through the center of the fruit where the spaces between calyx and pedicel are aligned; this is to elicit the chances of seed being hit. Local farmers suggest the number of calyces present in mangosteen plants represents the number of seeds inside. Cutting of the fruit was done using a sharp serrated knife or a new razor blade in one straight stroke. Cut fruits were blotted on a paper towel to dry prior to scanning.

\section{Image acquisition}

A box with $203.20 \times 279.40 \mathrm{~mm}$ measurement and $203.20 \mathrm{~mm}$ deep was used to cover during the process of scanning. The fruit was placed cut side down in the scanner where cut parts per sample were placed side by side with $50.8 \mathrm{~mm}$ distance from one another. Each fruit was placed in the scanner $25.4 \mathrm{~mm}$ apart per run to accommodate four to six samples based on size. Each scan was labeled below the fruit based on batch. Consistency of the quality of the scan was a priority which was attributed to noninterference of light on any part or portion of the cover to obtain correct scan and image resolution. Total blackness in the background of the scan is a requirement to prevent interface with the analysis. Soft tissue remnants in the scanner were cleaned with $70 \%$ ethyl alcohol for every run.

Scanned images were cropped to smoothen the borders of the picture. Calibration of the scanner was done every scan to ensure consistency of the color data obtained and the presence of light source after every scan. Images obtained were saved in one folder in a JPEG file.

\section{Analysis of parameters using Tomato Analyzer 4.0}

This procedure was based on the protocol of the study conducted by Rodriguez et al. (2010) using the same and updated software, Tomato Analyzer 4.0. Each scanned image of the fruits was uploaded in the software and the settings were adjusted to contain the following parameters: Basic Measurements, Fruit Shape Index, Homogeneity, Asymmetry, Internal Eccentricity, Latitudinal Sections, and Morphometrics (Gonzalo et al. 2009). The file was exported in $* \operatorname{csv}$ format and processed through Microsoft 
Excel 2016 version. The averages of each parameter were determined and treated in SPSS software version 22 to analyze if there is a significant difference between the two groups of mangosteen in terms of the above-mentioned parameters.

\section{Analysis of data}

The summarized data in MS Excel Format was imported to SPSS version 22 for statistical analysis. The data underwent a test of homogeneity of variances (HOV) before it proceeded to the test of significant differences. For the parameters which exhibited HOV, Analysis of Variance (ANOVA) and F-test were used while for the variables that did not exhibit HOV, Welch F-test was used to address skewed data distributions.

\section{RESULTS AND DISCUSSION}

\section{Results}

The total number of mangosteen fruits used in the study was 100 samples picked from different mangosteen trees in Quezon Province in Luzon and Davao-Zamboanga Provinces in Mindanao. Preliminary survey on mangosteen trees in two islands showed that there was variation in canopy shape, leaf size, rind thickness, fruit weight and diameter, rind thickness, and number of fruit per cluster (Mansyah et al. 2013). Further observations indicated more distinct morphological variations. The fruits can be divided into two types, round and pointed (Mansyah et al. 2003).

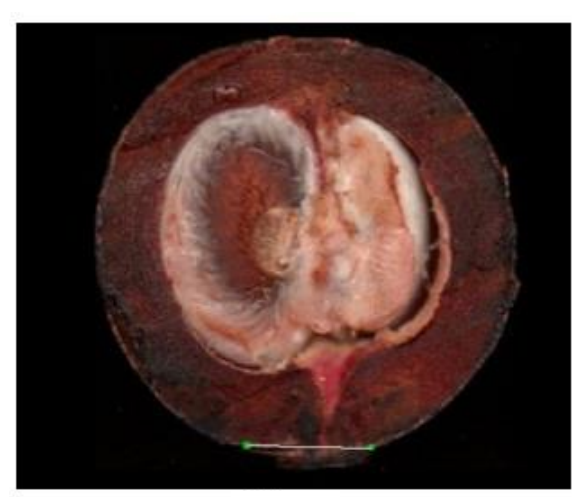

$\mathbf{A}$

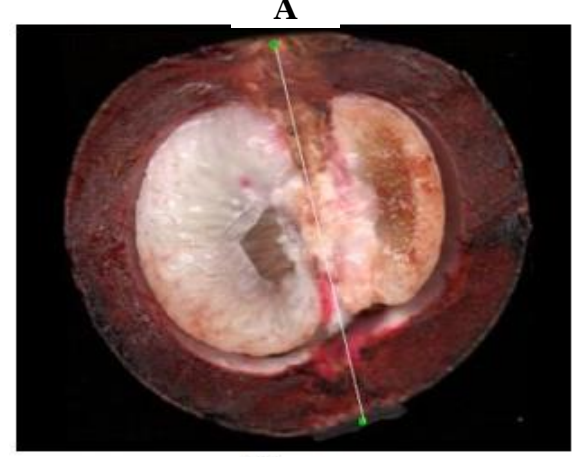

C

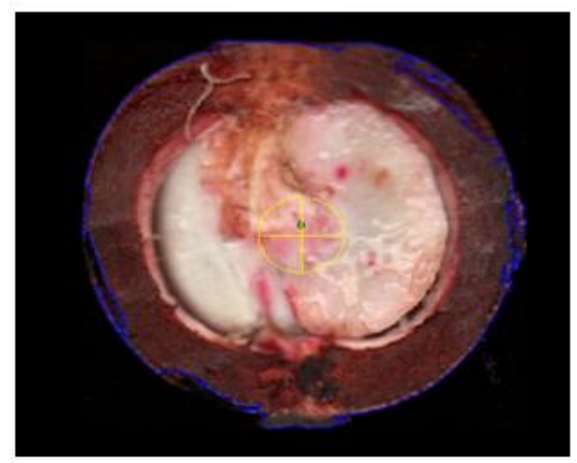

$\mathbf{E}$

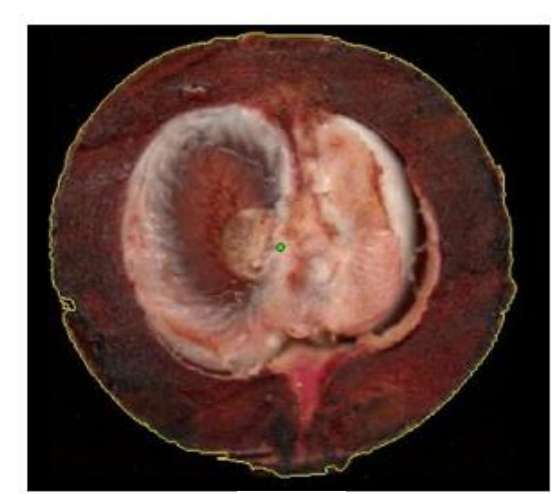

$\mathbf{B}$

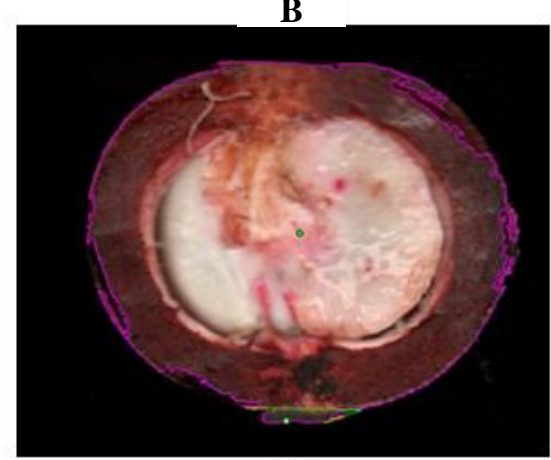

D

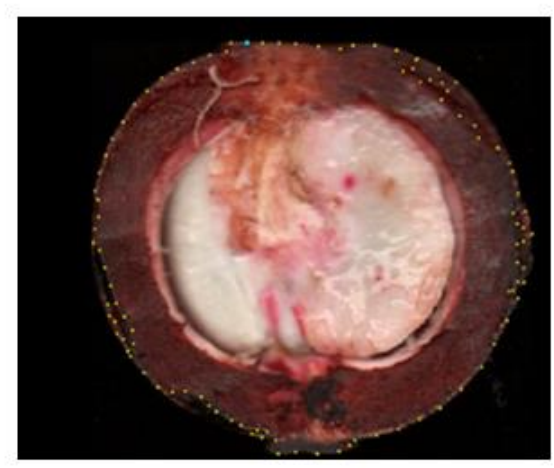

$\mathbf{F}$

Figure 1. Some parameters measured such as: A. Pericarp boundary, B. Measurement of ellipse, C. Distal protrusion, D. Distal fruit end shape, E. Internal Eccentricity, F. Morphometrics (3x,3y) 
Intensive research in both fruits found more characters that could enrich the mangosteen features. The fact could be seen when the fruits from different locations were collected together at the same time and then compared with each other. The important characters found were lobe shape, size, and thickness, and pedicel length (Mansyah et al. 2014). Variations of morphological characters of mangosteen obtained and proportion of each character based on the used fruit samples observed are shown in succeeding tables.

The two identified fruits of $G$. mangostana morphologically similar to $G$. malaccensis from different geographical areas in the Philippines are native and known as one of the most desirable tropical fruits of Southeast Asia (Narze 2010), has been considered as an obligate agamospermous hybrid (Richards 2010). These species have common important features based on fruit flowers, petal and leaf colors, presence and shape of pistilloIdes, and glandular line patterns (Kusumawati 2017). To differentiate the two sets of samples, Table 1 summarizes the manual measurements of specimens in this study which includes the fruit diameter $(\mathrm{cm})$ and fruit weight $(\mathrm{g})$.

For the pointed mangosteen, the average fruit diameter is $51.46 \mathrm{~mm}$ while its average fruit weight is $69.91 \mathrm{~g}$. For the rounded mangosteen, the average fruit diameter is $40.53 \mathrm{~mm}$ while its average fruit weight is $42.72 \mathrm{~g}$. The results show that the pointed mangosteen ( $G$. mangostana) specimen is larger than the rounded mangosteen specimen due to its different fruit shape compared to G. malaccensis from the province of Quezon in Luzon. This shows that the two kinds of mangosteens have many features in common like canopy shape, leaf size, rind thickness, fruit weight and diameter, rind thickness and number of fruit per cluster (Yapwattanaphun et al. 2004; Sweeney 2008).

Meanwhile, Table 2 shows another set of data from Tomato Analyzer 4.0 Version (Latest version) as the main software to analyze the basic measurements of the two fruit specimens. Table 2 contains a summary of the basic measurement comparing the two specimens. Using the analysis of variance, all of the parameters have significant differences in terms of the stated parameters for the two variants of mangosteens. The p-value of all parameters is below 0.05 , thus, significant differences were observed. This result happens because the sizes of the specimens are not the same during observations. During the laboratory process, the two fruit samples from different geographical areas in the Philippines were dissimilar in shapes as highly significant $(p=0.00)$ as indicated in Table 3.

Table 3 summarizes the fruit shape index across the set parameters. Using the analysis of variance, there are significant differences between the parameters set under fruit shape index. the $p$-value of the following parameters is below 0.05 , thus, all the variables can be considered significant. The measurements of these parameters were determined by ratio thus the size of the mangosteens does not affect its results. Based on these parameters, two mangosteens are significantly different from each other aside from they are geographically isolated.
Table 4 summarizes the results of modernity of mangosteen fruits. Based on the result of analysis of variance (ANOVA), significant differences were observed under ellipsoid and circular parameters while no significant difference was observed under rectangular parameters. the two parameters have different characters in terms of their shape, ellipsoid, and circular but share the same characteristics in terms of rectangular perspective.

Table 5 summarizes the data for the latitudinal section. The research suggests that the two mangosteens share the same characteristics in terms of lobeness degree and the ratio of their fruit pericarp area and thickness. Based on the three parameters of this data, the two mangosteens share the same characteristics in the latitudinal section.

Table 6 summarizes the numbers of morphometric landmarks of G. mangostana and G. malaccensis fruits. Based on the four sets of morphometrics, it was found out that the second set (at the calyx) obtained a not significant difference while the three sets have obtained significant differences. the two mangosteens share the same characteristics along the calyx area while differ on the tip part, along pericarp, and along mid-sagittal cut.

Table 7 summarizes the result of color test conducted for the two groups of mangosteens. Using Welch F-test, there were no significant differences observed in the color test specifically on the averages of red green and blue including the average luminosity. So, the presence of the accessions mentioned above gives more information on the morphological variations and characteristics $G$. mangostana and $G$. malaccensis. Among the morphological variations obtained, there were 7 specific characters that can be used to distinguish mangosteen accessions. These characters are ellipsoidal, circular, rectangular, lobe shape, size, pericarp area, and pericarp thickness. Thus, the G. mangostana and G. malaccensis fruits share the same characteristics in terms of the shade of colors.

\section{Discussion}

The results showed that the G. mangostana and $G$. malaccensis fruits had phenotypic similarities (Nazre 2018). In many cases, specific morphological characters of mangosteen from the different provinces varied. This was indicated by the rounded accessions from Quezon Province and ellipsoid lobe accessions from Davao-Zamboanga Provinces. Accessions with irregular in fruit shape were noticed as examined from the software. Further, based on the morphology characters the mangosteen in Quezon Province and Davao-Zamboanga Provinces could be considered into two varieties with round and pointed fruits. With this, the fruit measurement is a process in which to determine the parameters of pointed and rounded based on its fruit diameter and weight. This shows that the two varieties of mangosteens have many features in common (Wang et al. 2017) but it some features they matter from each other.

Additionally, it is distinguishable that morphological differences could be detected even within the populations in certain areas where they typically grew (Abdullah et al. 
2012). In addition, this indicates that the diversity of species must be considerable heterozygosity present within the accessions, reflecting the origin or parental differences of species in an area (Nakawajanaet al. 2016), Hence, it suggests that it is predominantly expected that the species (Mangostana) grow differently in terms of other features/characteristics even if it is originated from their common species as suggested by Mansyah et al. (2012; 2014) and Abdullah et al. (2012). This inquiry, proposes the observations of these two varieties of mangosteens $(G$. mangostana and $G$. malaccensis) with at least two possibilities regarding its origin in the country and it may lead to a proposition of truly be a hybrid from one species (Phopin et al. 2017).
As indicated above, the methods for calculating its parameters was based on the protocol of the study conducted by Rodriguez et al. (2010)-Tomato Analyzer 4.0. The process of scanning the image of the fruit section was uploaded in the software where its settings were adjusted to comprise the fruit parameters. Inclusive fruit measurements include fruit shape index, homogeneity, asymmetry, internal eccentricity, latitudinal sections, and morphometrics (Ghasemzadeh et al. 2018). The averages of each parameter were determined and correlated between the two groups of mangosteens' parameters. In this study, parameters' measurements of mangostana fruits have several advantages, relatively more accurate because the software is in the latest version in order to get all the parameters needed in the study.

Table 1. Manual measurements of specimens

\begin{tabular}{|c|c|c|c|c|c|c|}
\hline \multirow{2}{*}{ Plant species } & \multirow{2}{*}{ Locality } & \multirow{2}{*}{ No. of samples } & \multicolumn{2}{|c|}{ Fruit diameter } & \multicolumn{2}{|c|}{ Fruit weight } \\
\hline & & & Mean $(\mathbf{m m})$ & SD & Mean (g) & SD \\
\hline Pointed (G. mangostana) & Davao-Zamboanga & 50 & 51.46 & 3.86 & 69.91 & 15.99 \\
\hline Rounded (G. malaccensis) & Quezon & 50 & 40.53 & 4.30 & 42.72 & 15.52 \\
\hline
\end{tabular}

Table 2. Summary of basic measurements comparing the two specimens

\begin{tabular}{|c|c|c|c|c|c|}
\hline $\begin{array}{l}\text { Parameters } \\
\text { (on average) }\end{array}$ & $\begin{array}{c}\text { Pointed mangosteen } \\
(\text { G. mangostana })\end{array}$ & $\begin{array}{c}\text { Rounded mangosteen } \\
\text { (G. malaccensis })\end{array}$ & F-test & p-value & Remarks \\
\hline Perimeter $(\mathrm{mm})$ & 127.58 & 83.58 & 146.57 & 0.000 & Significant \\
\hline Area $\left(\mathrm{mm}^{2}\right)$ & 416.42 & 227.63 & 424.53 & 0.000 & Significant \\
\hline Width mid-height (mm) & 23.60 & 18.07 & 330.57 & 0.000 & Significant \\
\hline Maximum width (mm) & 24.20 & 18.45 & 327.73 & 0.000 & Significan \\
\hline Height mid-width (mm) & 22.46 & 15.70 & 421.17 & 0.000 & Significan \\
\hline Maximum height (mm) & 22.96 & 16.13 & 429.33 & 0.000 & Significan \\
\hline Curved height (mm) & 36.56 & 24.09 & 153.24 & 0.000 & Significan \\
\hline
\end{tabular}

Table 3. Fruit shape index

\begin{tabular}{|c|c|c|c|c|c|}
\hline $\begin{array}{l}\text { Parameters } \\
\text { (on average) }\end{array}$ & $\begin{array}{c}\text { Pointed mangosteen } \\
(\text { G. mangostana })\end{array}$ & $\begin{array}{c}\text { Rounded mangosteen } \\
\text { (G. malaccensis })\end{array}$ & F-test & p-value & Remarks \\
\hline Fruit shape index (external) & 0.953 & 0.875 & 66.217 & 0.000 & Significant \\
\hline Curve fruit shape index & 1.57 & 1.39 & 10.951 & 0.001 & Significant \\
\hline Asymmetry & 0.154 & 0.039 & 15.566 & 0.000 & Significant \\
\hline $\begin{array}{l}\text { Fruit shape index (internal) / } \\
\text { internal eccentricity }\end{array}$ & 0.956 & 0.868 & 68.298 & 0.000 & Significant \\
\hline
\end{tabular}

Table 4. Homogeneity of mangosteen fruits

\begin{tabular}{lccccc}
\hline $\begin{array}{c}\text { Parameters } \\
\text { (on average) }\end{array}$ & $\begin{array}{c}\text { Pointed mangosteen } \\
(\text { G. } \text { mangostana) }\end{array}$ & $\begin{array}{c}\text { Rounded mangosteen } \\
(\text { G. malaccensis) }\end{array}$ & F-test & p-value & Remarks \\
\hline Ellipsoid & 0.105 & 0.077 & 15.566 & 0.000 & Significant \\
Circular & 0.110 & 0.089 & 6.314 & 0.013 & Significant \\
Rectangular & 0.489 & 0.489 & 0.009 & 0.926 & Not significant \\
\hline
\end{tabular}

Table 5. Latitudinal section

\begin{tabular}{lccccc}
\hline $\begin{array}{l}\text { Parameters } \\
\text { (on average) }\end{array}$ & $\begin{array}{c}\text { Pointed mangosteen } \\
(\text { G. mangostana })\end{array}$ & $\begin{array}{c}\text { Rounded mangosteen } \\
(\text { G. } \text { malaccensis })\end{array}$ & F-test & p-value & Remarks \\
\hline Lobedness Degree & $2.79^{\circ}$ & $3.08^{\circ}$ & 2.923 & 0.089 & Not significant \\
Fruit pericarp area (ratio) & 0.440 & 0.443 & 1.131 & 0.289 & Not significant \\
Fruit pericarp thickness (ratio) & 0.799 & 0.799 & 2.268 & 0.134 & Not significant \\
\hline
\end{tabular}


Table 6. Morphometric analysis

\begin{tabular}{|c|c|c|c|c|c|c|}
\hline \multirow[t]{3}{*}{ Mangosteen } & \multicolumn{6}{|c|}{ Number of morphometric landmarks } \\
\hline & \multicolumn{3}{|c|}{$(1 x, 1 y)$-one landmark, tip } & \multicolumn{3}{|c|}{$(2 x, 2 y)$-two landmarks, at the calyx } \\
\hline & F-test & p-value & Remarks & F-test & $p$-value & Remarks \\
\hline Pointed & 56.46 & 0.000 & significant & 28.91 & 0.091 & not significant \\
\hline \multicolumn{7}{|l|}{ Rounded } \\
\hline \multirow[t]{3}{*}{ Mangosteen } & \multicolumn{6}{|c|}{ Number of morphometric landmarks } \\
\hline & & ree landm & pericarp & & ur landma & agittal cut \\
\hline & $F$-test & $p$-value & Remarks & $F$-test & $p$-value & Remarks \\
\hline $\begin{array}{l}\text { Pointed } \\
\text { Rounded }\end{array}$ & 7.040 & 0.009 & significant & 69.70 & 0.000 & significant \\
\hline
\end{tabular}

Table 7. Color test for the mangosteen fruits

\begin{tabular}{lccccc}
\hline $\begin{array}{l}\text { Parameters } \\
\text { (on average) }\end{array}$ & $\begin{array}{c}\text { Pointed mangosteen } \\
(\text { G. mangostana) }\end{array}$ & $\begin{array}{c}\text { Rounded mangosteen } \\
(\text { G. malaccensis })\end{array}$ & Welch F-test & p-value & Remarks \\
\hline Average red & 116.489 & 116.689 & 0.005 & 0.944 & Not significant \\
Average green & 80.538 & 83.908 & 1.357 & 0.247 & Not significant \\
Average blue & 70.044 & 74.734 & 2.376 & 0.126 & Not significant \\
Average luminosity & 87.729 & 89.952 & 0.668 & 0.409 & Not significant \\
\hline
\end{tabular}

Meanwhile, as presented in Table 3, it revealed the appearance of fruit shape index, curve fruit shape index, asymmetry, and internal eccentricity. It shows that the pvalue $(\mathrm{p}<0.00)$ of all the parameters of the fruit shape index having significant difference as the measurement of these parameters was determined by ratio in order not to affect its results when compared to the other parameters. So, from the data analysis in this study, distribution data is significantly different from Quezon Province in Luzon and Davao-Zamboanga Provinces in Mindanao. The homogeneity of variance test data F-test obtained is significant indicating different data is not homogeneous. Because the different parameters are not homogeneous so as to determine differences in the features of mangosteen pericarp extract from G. mangostana and G. malaccensis fruits (Fauza et al. 2015).

As presented in Table 4, the two mangosteens vary in terms of its ellipsoid and circular shape. Further, there is not much information on how it varies when it comes to their fruit shapes but some literature reported that environmental factors were possibly considered for its fruit variations like the fertility of soil, weather, or climate (Phopin et al. 2017). This suggests that defining the best agronomic practices is vital for mangosteen improvement and could result in potential non-genetic gains such as early fruiting and improved yields. Already, several growers have reported noticeable improvements in fruit yields and tree performance in response to modified cultural practices (like shading of trees or pruning techniques). Hence these may account for the reported minor dissimilarities between mangosteen trees and mangosteen plantations, and not genetic factors (Muchtaridi et al. 2017).

Additionally, similarity of latitudinal sections was observed including lobedness degree, ratio of the fruit pericarp area, and ratio of the fruit pericarp thickness as presented in Table 5. Meanwhile, in terms of the morphometric landmarks of the two mangosteens presented in Table 6, the two mangosteens share the same characteristics along with the calyx while variations were observed on the tip part, along with pericarp, and along mid-sagittal cut of these two mangosteens. The use of four sets of landmarks shows that these two mangosteens exhibit variations and the color test presented in Table 7 exemplified that the two mangosteens share the same characteristics in terms of shades of color, averages of red, green, blue, and luminosity.

The present study found out limited published literature review regarding these two mangostana species in the Philippines. As indicated by Nazre (2014), limited sources stating differences in fruit morphometric of G. mangostana and $G$. malaccensis in the country. Hence, it recommends that this study requires research with larger samples to determine its fruit morphometric diversity. Therefore it is necessary for the future to find more varieties of mangostana in the different islands of the country to give updates and to uplift mangostana farming and propagate quality fruits. As claimed by Sobir et al. (2013), it warrants that $G$. mangostana and $G$. malaccensis form single interrelated taxon. With this, previous publications treated $G$. mangostana and G. malaccensis species rooted from single species and these domesticated mangosteens could still be recognized at the varietal level. Maybe a taxonomic recognition by the biologists is underway, including proper taxonomic treatments of the varieties of these species.

This evidence needs to be confirmed by molecular observation to confirm the variations are genetic traits or affected by environment. A genetic study of these accessions obtained by molecular marker is still being conducted. Based on this research, it is necessary to confirm the important characters which can be used to distinguish the mangosteen. This might be the first report on the morphology variations/characters of mangosteens in the Philippines. Lastly, this information will be useful for future researchers who have an interest in mangosteen 
investigation and evaluation, not only to these 3 provinces but to most areas in the country.

To conclude, based on the findings, the morphological variability of mangosteen in Quezon Province, Luzon, and Davao-Zamboanga Provinces in Mindanao could be divided into two varieties: $G$. mangostana and $G$. malaccensis. It also pointed out that the parameters of the two mangosteens were observed to its fruit shape indices (internal and external), curved fruit shape index, asymmetry such as ellipsoidal, ovoid, and circular. While the shared characteristics were found between the two varieties of mangosteen like lobedness degree, fruit pericarp area, fruit pericarp thickness, and shade of color as provided by the color test. Lastly, morphological study showed that mangosteen has phenotypic variations with specific characters that could be used to distinguish mangosteen varieties in the Philippines.

\section{ACKNOWLEDGEMENTS}

The authors express their appreciation to the Science and Technology Research Center (STRC) of De La Salle University, Manila, Philippines for the laboratory equipment used by the researchers in advanced systematics.

\section{REFERENCES}

Abdullah H. 2012. Studies in Garcinia, dioecious tropical forest trees: the origin of the mangosteen (G. mangostana L.). Bot J Linn Soc. 103 (4): 301-308

Aizat W, Jamil I, Ahmad-Hashim F, Normah M. 2019. Recent updates on metabolite composition and medicinal benefits of mangosteen plant Peer J 7: 6324

Altendorf S. 2018. Minor tropical fruits: mainstreaming a niche market. Food and Agriculture Organization of the United Nations. FAO, Rome.

Borba E, Funch R, Ribeiro P, Smidt E, Silva-Pereir V. 2017. Demography, a genetic and morphological variability of the endangered Sophronitis sincorana (Orchidaceae) in the Chapada Diamantina, Brazil. Plant Syst Evol 267: 129-146.

Burkill, I. 2015. Fruit characteristics and properties of four Garcinia (Clusiaceae) fruit species. Fruit J 71 (4): 199-207.

DA-AMAS. 2014. Agribusiness and Marketing Assistance Service. Mangosteen Industry Situation Report, http://www.philonline.com.ph/-webdev/da-amas/mangostee.html

Dryden L. 2014. Comparison of the biological activity of two different isolates from mangosteen. J Adv Res 20: 61-70.

Cruz F. 2011. Status report on genetic resources of Mangosteen (Garcinia mangostana L.) in Southeast Asia. IPGRI Office for South Asia, Delhi.

Fauza H, Karmana M, Rostini N, Mariska I. 2015. Growth and phenotypic variability of gamma-ray irradiated mangosteens. Zuriat 16 (2): 133-144.

Ghasemzadeh A, Jaafar H, Baghdadi A, Tayebi-Meigooni A. 2018. Alpha-mangostin-rich extracts from mangosteen pericarp: Optimization of green extraction protocol and evaluation of biological activity. Molecules 23: 1852. DOI: 10.3390/molecules23081852.

Gonzalo M, Brewer M, Anderson C, Sullivan D, Gray S, van der Knaap E, Am J. 2009. Tomato fruit shape analysis using morphometric and morphology attributes implemented in Tomato Analyzer Software Program. Soc Hort Sci 134: 77-87.

Hapsari D, Poerwanto R. Sopandie D, Santosa E. 2018. Partial root-zone irrigation effects on growth and calcium status of mangosteen seedling (Garcinia mangostana L.). Adv Hortic Sci 32: 49-59.

Henderson A. 2014. Traditional morphometrics in plant systematics and its role in palm systematics. Bot J Linn Soc 151: 103-111.

Kusumawati N, Santoso A, Sianita M, Muslim S. 2017. Extraction characterization and application of fresh mangosteen (Garcinia mangostana L.) peel. Intl J Adv Sci Eng Inf Technol 7: 878-884.
Mansyah E, Baihaki A, Setiamihardja R, Darsa J, Sobir, Poerwanto R. 2004. Phenotypic variability of mangosteen (Garcinia mangostana L.) at several production centres in Java. Jurnal Hortikultura13: 147-156.

Mansyah E, Baihaki A, Setiamihardja R, Darsa JS, Sobir, Poerwanto R. 2014. Analisis variabilitas genetik manggis (Garcinia mangostana L.). Zuriat 4 (1): 35-44. [Indonesian]

Mansyah E, Santoso PJ, Muas I, Sobir. 2013. Evaluation of genetic diversity among and within mangosteen (Garcinia mangostana L.) trees. $4^{\text {th }}$ International Symposium on Tropical and Subtropical Fruits. Bogor, West Java. Indonesia. November 3-7, 2013.

Matra D, Poerwanto R, Santosa E, Higashio H, Anzai H, Inoue E. 2016. Analysis of allelic diversity and genetic relationships among cultivated mangosteen (Garcinia mangostana L.) in Java, Indonesia using microsatellite markers and morphological characters. Trop Plant Biol 9: 29-41.

Muchtaridi M, Puteri N, Milanda T, Musfiroh I. 2017. Validation analysis methods of a mangosteen and gartanin mixture in mangosteen (Garcinia mangostana L.) fruit grind extract from West Java with HPLC. J Appl Pharm Sci 7 (10): 125-130.

Nakawajana N, Terdwongworakul A, Teerachaichayut S. 2016. Minimally destructive assessment of mangosteen translucency based on electrical impedance measurements. J Food Eng 171: 137-144.

Nazre M. (2010) Historical review and notes on the correct scientific name for seashore mangosteen. Genet Resour Crop Evol 57: 1249-1259.

Nazre M, Newman M, Pennington R, Middleton D. 2018. Taxonomic revision of Garcinia section Garcinia (Clusiaceae). Phytotaxa 373: 1-52.

Nazre M. 2014. New evidence on the origin of mangosteen (Garcinia mangostana L.) based on morphology and ITS sequence. Genet Resour Crop Evol 61: 1147-1158.

Osman M, Milan A. 2006. Mangosteen-Garcinia mangostana L. Southampton Centre for Underutilized Crop, University of Southampton, Southampton, UK.

Ounlert P, Sdoodee S, Tongkhow P. 2017. The mangosteen flowering date model in Nakhon Si Thammarat Province, Southern Thailand. J Cent Eur Agric 18: 168-183.

Ovalle-Magallanes B, Eugenio-Pérez D, Pedraza-Chaverri J. 2017. Medicinal properties of mangosteen (Garcinia mangostana L.): a comprehensive update. Food Chem Toxicol 109: 102-122.

Palapol Y, Ketsa S, Stevenson D, Cooney J, Allan A, Ferguson I. 2014. Color development and quality of mangosteen (Garcinia mangostana L.) fruit during ripening and after harvest. Postharvest Biol Technol 51: 349-353.

Perez P, Pedraza-Chaverri J, Cárdenas-Rodríguez N, Orozco-Ibarra M, Pérez-Rojas JM. 2012. Medicinal properties of mangosteen (Garcinia mangostana). Food Chem Toxicol 46: 3227-3239.

Phopin K, Wanwimolruk S, Prachayasittikul V. 2017. Queen of fruits mangosteen (Garcinia mangostana L.). J Sci Food Agric 97: 832-840.

Qin Y, Sun Y, Li L, Xie L, Deng Z, Chen H. 2017. Characterization and antioxidant activities of procyanidins from lotus seedpod, mangosteen pericarp. Intl J Food Prop 20: 1621-1632.

Ramage C, Sando L, Peace C, Carroll B, Drew R. 2004. Genetic diversity revealed in the apomictic fruit species Garcinia mangostana L. (mangosteen). Euphytica1 36: 1-10.

Richards A. 2010. Studies in Garcinia, dioecious tropical forest trees: the origin of mangosteen. Bot J Linn Soc 103: 301-308.

Sandra F. 2011. Image processing application for mangosteen grading with non-destructive method. J Appl Sci Res 7 (12): 1890-1894.

Sando L, Peace C, Ramage C, Carroll B, Drew R. 2011. Assessment of genetic diversity in Australian-grown mangosteen (Garcinia mangostana L.) and its wild relatives. Acta Hortic 692: 143-148.

Sobir, Poerwanto R, Santosa E, Sinaga S, Mansyah E. 2013. Genetic variability of mangosteen, an apomictic Garcinia. Acta Hortic 975, 155-164.

Wang M, Zhang K, Gu Q, Bi X, Wang J. 2017. Pharmacology of mangosteens and their derivatives: a comprehensive review. Chin $\mathrm{J}$ Nat Med 15: 81-93.

Wang J, Sanderson BJ, Zhang W. 2011. Cytotoxic effect of xanthones from pericarp of the tropical fruit mangosteen (Garcinia mangostana Linn.) on human melanoma cells. Food Chem Toxicol 49: 2385-2391.

Wester P. 2011. Edible Garcinias and possible mangosteen stocks. J Dept Agric Puerto Rico 3 (4): 283-305.

Whidhiasih R, Guritman S, Supriyo P. 2012. Identification of mangosteen maturity stage based on color using fuzzy neural network. J Tek Ind Pertanian 22 (2): 82-91. 